\title{
Resposta de vacas leiteiras à substituição parcial de farelo de soja por ureia encapsulada
}

[Response of lactating cows to the partial replacement of soybean meal by encapsulated urea]

\author{
J.F. Santos ${ }^{1}$, G.S. Dias Júnior ${ }^{2}$, L.L. Bitencourt ${ }^{2}$, N.M. Lopes $^{2}$, S. Siécola Júnior ${ }^{2}$, \\ J.R.M. Silva ${ }^{3}$, R.A.N. Pereira ${ }^{4}$, M.N. Pereira ${ }^{2 *}$ \\ ${ }^{1}$ Cooperativa Castrolanda - Castro, PR \\ ${ }^{2}$ Universidade Federal de Lavras \\ Caixa Postal 3037 \\ 37200-000 - Lavras, MG
}

${ }^{3}$ Instituto Federal de Educação - Ciência e Tecnologia do Norte de Minas Gerais - Januária, MG

${ }^{4}$ Empresa de Pesquisa Agropecuária de Minas Gerais - Unidade Regional EPAMIG Sul de Minas - Lavras, MG

\section{RESUMO}

Avaliou-se a substituição parcial de farelo de soja na dieta-controle por ureia encapsulada ou por ureia, ambos acrescidos de polpa cítrica. Dezoito vacas foram alocadas a uma sequência de três tratamentos, em seis quadrados latinos 3x3, com períodos de 21 dias. O teor de proteína bruta nas dietas foi 15,5\%, cerca de 1,5\% oriundo de nitrogênio não proteico (NNP). O uso de NNP reduziu o consumo diário de matéria seca em $0,8 \mathrm{~kg}$ $(P=0,04)$, sem influenciar a produção de leite $(31,5 \mathrm{~kg}, P=0,98)$. A conversão do alimento em leite foi menor na dieta-controle $(P<0,09)$. As fontes de NNP aumentaram o teor de $\mathrm{N}$-ureico no plasma (NUP) duas horas após a alimentação da manhã $(P=0,06)$. A frequência de NUP acima de $22,0 \mathrm{mg} / \mathrm{dL}$ foi maior com ureia $(P<0,01)$, similarmente ao observado para o teor e a secreção diária de $\mathrm{N}$-ureico no leite $(P<0,01)$. A substituição de farelo de soja por NNP e polpa cítrica melhorou a eficiência alimentar, sem afetar o balanço de nitrogênio.

Palavras-chave: vaca de leite, balanço de nitrogênio, nitrogênio ureico

\begin{abstract}
The partial replacement of the soybean meal in the control diet for encapsulated urea or urea, both with added citrus pulp was evaluated. Eighteen Holstein cows were allocated to a sequence of the three treatments, in six $3 \times 3$ latin squares, with 21-day periods. The dietary level of crude protein was $15.5 \%$, around 1.5\% from nonprotein nitrogen $(N P N)$. The use of NPN reduced $0.8 \mathrm{~kg}$ of daily dry matter intake $(P=0.04)$, without affecting milk yield (31.5kg, $P=0.98)$. The conversion of feed into milk decreased for the control diet $(P<0.09)$. The NPN sources increased plasma urea- $N$ (PUN) two hours after the morning feeding $(P=0.06)$. The frequency of PUN above $22.0 \mathrm{mg} / \mathrm{dL}$ was increased by urea $(P<0.01)$, similarly to the observed for milk urea- $N$ content and daily secretion $(P<0.01)$. The replacement of soybean meal for NPN and citrus pulp improved feed efficiency, without affecting the nitrogen balance.
\end{abstract}

Keywords: dairy cattle, nitrogen balance, urea-nitrogen

\section{INTRODUÇÃO}

A substituição de alimentos que contenham proteína verdadeira por alimentos com maior teor de nitrogênio na forma de nitrogênio não proteico (NNP), como a ureia, pode melhorar a eficiência financeira da alimentação e reduzir a necessidade de compra e estocagem de concentrados proteicos; além disso, possibilita a formulação de dietas com maior inclusão ou de alimentos energéticos, ou de subprodutos fibrosos, ou de forragens. Esta estratégia explora a capacidade de ruminantes de sintetizar proteína microbiana de alto valor biológico a partir de NNP.

Recebido em 10 de março de 2010

Aceito em 21 de março de 2011

*Autor para correspondência (corresponding author)

E-mail: mpereira@dzo.ufla.br 
Entretanto, a rápida hidrólise da ureia por ureases microbianas pode resultar em disponibilidade ruminal de $\mathrm{N}$ amoniacal em taxa superior à capacidade de síntese de proteína microbiana, resultando em perda excessiva de $\mathrm{N}$ do rúmen para o sangue (Lapierre e Lobley, 2001). Acima de $70 \%$ do $\mathrm{N}$ ingerido por vacas leiteiras podem ser perdidos nas fezes e na urina (Tamminga, 1992). Esse fato é preocupante quando são considerados seus possíveis impactos negativos sobre o ambiente (Smith e Frost, 2000). Aumento excessivo no teor de $\mathrm{N}$ na forma de ureia e amônia no sangue e em tecidos também pode ter impacto negativo sobre a fisiologia animal, especialmente sobre a reprodução (Butler, 1998).

A ureia é fisicamente encapsulada por ceras vegetais (Optigen ${ }^{\circledR}$ II, Alltech Inc., Nicholasville, USA) visando reduzir a velocidade de liberação do $\mathrm{N}$ no rúmen. Já foram observadas tendências de aumento na síntese microbiana in vitro, quando o Optigen ${ }^{\circledR}$ II substituiu a ureia (Harrison et al., 2006), e aumento na produção de leite, quando substituiu parcialmente o farelo de soja (Inostroza et al., 2010). Entretanto, não foram encontrados, na literatura consultada, trabalhos que avaliassem a resposta do balanço de $\mathrm{N}$ e do teor de nitrogênio ureico no plasma (NUP) quanto à substituição de farelo de soja pelo produto. O objetivo desde trabalho foi avaliar o desempenho, o balanço de nitrogênio e o NUP em resposta à substituição parcial e isoproteica do farelo de soja por polpa cítrica mais Optigen ${ }^{\circledR} \mathrm{II}$ e a substituição do farelo de soja pela mesma quantidade de $\mathrm{N}$ oriundo de ureia mais polpa cítrica.

\section{MATERIAL E MÉTODOS}

Dezoito vacas da raça Holandesa, com $150 \pm 82$ dias em lactação no início do período experimental, formaram seis grupos de três animais com base na ordem de parto e na produção de leite. Dois grupos foram formados por primíparas $(624 \pm 35 \mathrm{~kg})$, e os outros quatro por multíparas $(649 \pm 49 \mathrm{~kg})$. Dentro de cada grupo, as vacas foram aleatoriamente alocadas a uma sequência de três tratamentos, em delineamento do tipo quadrado latino 3x3, realizados simultaneamente, e com períodos de 21 dias. Mensurações foram realizadas na terceira semana de cada período experimental. Os tratamentos foram: dieta com farelo de soja como concentrado proteico (controle) e dietas em que a polpa cítrica e a fonte de NNP de liberação lenta - Optigen ${ }^{\circledR}$ II (Alltech Inc., Nicholasville, USA) - ou a ureia substituíram o mesmo teor dietético de farelo de soja (Tab. 1).

As dietas completas foram oferecidas às seis e às 14h, em quantidade suficiente para resultar em, no mínimo, $15 \%$ do oferecido como sobra diária. Entre os dias 15 e 20 de cada período, foi mensurado o consumo de matéria seca (CMS). Foram coletadas amostras diárias de cada ingrediente e das sobras alimentares por animal, e amostras compostas foram formadas com base em quantidades idênticas de matéria natural. Essas foram desidratadas em estufa de ventilação forçada por $72 \mathrm{~h}$ a $55^{\circ} \mathrm{C}$, trituradas em peneira de $1 \mathrm{~mm}$ em moinho do tipo Thomas-Willey, e uma subamostra foi desidratada em estufa de $100^{\circ} \mathrm{C}$ por $24 \mathrm{~h}$ para determinação da matéria seca. O teor de extrato etéreo foi determinado segundo o AOAC (Official..., 1990), as cinzas por incineração da amostra em mufla por oito horas a $550^{\circ} \mathrm{C}$, o teor de FDN por um ANKON $^{\circledR}$ Fiber Analyser (ANKON Technology Corporation, Fairport, EUA), e o teor de nitrogênio dos alimentos e sobras foi determinado pelo método de microkjeldhal (Official..., 1975).

As vacas foram ordenhadas três vezes ao dia. Amostras de leite foram coletadas em frascos com 2-bromo-2-nitropropano-1-3-diol de seis ordenhas consecutivas, nos dias 15 e 16 de cada período experimental. Em cada amostra, foram determinados os teores de gordura, proteína, lactose e NUL (PARLPR, Curitiba, PR).

No dia 17 de cada período, foi avaliado o comportamento ingestivo por observação visual da atividade bucal a cada cinco minutos, durante as seis horas subsequentes à alimentação da manhã. As atividades bucais consideradas foram de ingestão de alimento, ingestão de água, ruminação e ócio. O tempo da primeira refeição - refeição condicionada - e das outras refeições foi calculado em múltiplos de cinco minutos, e o número de refeições matinais foi determinado. $\mathrm{O}$ consumo de matéria seca foi mensurado, e a taxa de ingestão matinal foi calculada $\left(\mathrm{g} \mathrm{min}^{-1}\right)$. Neste mesmo dia, a proporção do consumo diário entre seis e $12 \mathrm{~h}$ (manhã), 12 e $20 \mathrm{~h}$ (tarde) e 20 e seis horas (noite) foi obtido por mensuração do oferecido e das sobras alimentares em cada intervalo. 
Tabela 1. Composição das dietas oferecidas, em ingredientes, e das dietas consumidas, em nutrientes, segundo os tratamentos para vacas leiteiras

\begin{tabular}{lccc}
\hline \multirow{2}{*}{ Ingrediente } & Optigen ${ }^{\circledR}$ II & Controle & Ureia \\
\cline { 2 - 4 } & & \% da matéria seca & \\
\hline Silagem de milho & 41,9 & 41,9 & 41,9 \\
Feno de tífton & 1,9 & 1,9 & 1,9 \\
Polpa cítrica & 15,9 & 12,6 & 16,0 \\
Milho maduro moído fino & 14,2 & 14,2 & 14,2 \\
Caroço de algodão & 7,6 & 7,6 & 7,6 \\
Farelo de soja & 14,1 & 18,0 & 14,1 \\
Optigen ${ }^{\circledR}$ II & 0,61 & & 0,56 \\
Ureia & & 3,9 & 3,9 \\
Premix ${ }^{1}$ & 3,9 & & \\
& & & 15,6 \\
Nutriente & & 15,5 & 1,59 \\
\hline Proteína bruta & 15,4 & 36,6 \\
Proteína bruta oriunda de nitrogênio não proteico & 1,54 & 35,9 & 23,5 \\
Fibra em detergente neutro total & 36,1 & 23,5 & 7,2 \\
Fibra em detergente neutro de forragens & 23,5 & 7,2 & 5,7 \\
Cinzas & 7,2 & 5,6 & 34,9 \\
Extrato etéreo & 5,7 & 35,8 & \\
Carboidratos não fibrosos ${ }^{2}$ & 35,6 & & \\
\hline
\end{tabular}

${ }^{1}$ Premix = 11,5\% de Ca; 1,3\% de P; 4,7\% de Mg; 0,3\% de S; 10,0\% de Na; 4,9\% Cl; 12,14 ppm de Co; 162 ppm de Cu; 405 ppm de Mn; 964 ppm de Zn; 6,64 ppm de Se; 16,20 ppm de I; 80988 UI de vitamina A; 17817 UI de vitamina D; 502 UI de vitamina E; 25\% de bicarbonato de sódio; 7\% de óxido de magnésio e 25\% de Megalac-E.

${ }^{2} \mathrm{CNF}=$ Carboidratos não fibrosos $=100-(\% \mathrm{~PB}+\% \mathrm{FDN}+\% \mathrm{EE}+\%$ Cinzas $)$

Nos dias 18 a 20, foram mensuradas tanto a produção fecal quanto a urinária por coleta total realizada por oito horas ininterruptas. O início do período de coleta foi atrasado em oito horas a cada novo dia, visando obter uma amostra representativa das 24 horas do dia. As fezes de cada vaca foram congeladas ao longo das coletas e formaram uma amostra composta ao final de cada período. Os compostos por vaca foram desidratados, e o teor de FDN, cinzas e nitrogênio foram analisados como previamente descrito. A digestibilidade aparente no trato digestivo total da matéria orgânica (DMO), da matéria seca (DMS), da FDN (DFDN) e da matéria orgânica não FDN (DMOnFDN) foi calculada.

Ao longo da coleta, toda a urina foi colocada em galões que continham $200 \mathrm{~mL}$ de solução de ácido sulfúrico a $10 \%$. O volume urinário foi mensurado, e uma amostra, formada por vaca, foi, então, congelada a $-20^{\circ} \mathrm{C}$, após diluição em quatro partes de água destilada. Na determinação do teor de alantoína, utilizou-se o procedimento usado por Chen e Gomes (1995). Para a análise de creatinina, foi utilizado kit laboratorial (Labtest Diagnóstica S.A., Lagoa Santa, MG, Cat. 35-100). O teor de nitrogênio na urina foi mensurado como previamente descrito.
No dia 21, amostras de sangue foram obtidas dos vasos coccígeos para dosagem de NUP. As amostras foram coletadas nos tempos de zero, duas, quatro, oito, 10 e 14 h após a alimentação matinal. $\mathrm{O}$ sangue, colhido em tubos heparinizados, foi centrifugado, e o plasma congelado a $-20^{\circ} \mathrm{C}$ para posterior análise de ureia (Doles Reagentes e Equipamentos para Laboratório Ltda., Goiânia, GO, kit ureia 500). O tempo diário de NUP acima de $21 \mathrm{mgdL}^{-1}$ foi calculado assumindo mudança linear na concentração plasmática entre dois tempos de amostragem.

A retenção de nitrogênio foi calculada subtraindo do nitrogênio ingerido o excretado no leite, nas fezes e na urina. O teor de nitrogênio no leite foi determinado por divisão do teor de proteína pelo fator 6,38. A eficiência alimentar foi calculada pelas relações entre produção de leite e CMS e produção de leite e consumo de proteína.

As variáveis com valor único em cada período foram analisadas pelo procedimento GLM do SAS (1985), com o seguinte modelo: $Y_{\mathrm{ijklm}}=\mu+$ $\mathrm{Q}_{\mathrm{i}}+\mathrm{V}_{\mathrm{j}(\mathrm{i})}+\mathrm{P}_{\mathrm{k}}+\mathrm{T}_{\mathrm{l}}+\mathrm{e}_{\mathrm{ijkl}}$, em que: $\mu=$ média geral, $\mathrm{Q}_{\mathrm{i}}=$ efeito de quadrado $(\mathrm{i}=1$ a 6$), \mathrm{V}_{\mathrm{j}(\mathrm{i})}=$ efeito de vaca dentro de quadrado $\left(\mathrm{j}=1\right.$ a 18), $\mathrm{P}_{\mathrm{k}}$ = efeito de período $(\mathrm{k}=1$ a 3$), \mathrm{T}_{1}=$ efeito de 
tratamento $\left(\mathrm{l}=\right.$ Optigen ${ }^{\circledR} \mathrm{II}$, controle, ureia), $\mathrm{e}_{\mathrm{ijkl}}=$ erro residual, assumido independente e identicamente distribuído em distribuição normal, com média zero e variância $\sigma^{2}$. Dois contrastes ortogonais com um grau de liberdade foram testados: 1) Optigen ${ }^{\circledR}$ II vs controle e 2) ureia vs controle.

O teor de NUP mensurado ao longo do tempo foi analisado como medidas repetidas pelo procedimento MIXED do SAS (Littell et al., 1996). Ao modelo anteriormente descrito, foram acrescidos os efeitos de tempo de amostragem zero, duas, quatro, oito, 10 e $14 \mathrm{~h}$ - e sua interação com tratamento. O quadrado médio para a interação entre quadrado, vaca, período e tratamento foi utilizado como medida de erro para testar o efeito de tratamento, enquanto o efeito de tempo e sua interação com tratamento foram testados usando-se o erro residual. As estruturas de covariância consideradas foram: simetria composta, autorregressiva de primeira ordem e não estruturada. A estrutura de covariância utilizada foi definida pelo critério de informação Akaike. A frequência de amostras sanguíneas com NUP acima de $22 \mathrm{mgdL}^{-1}$ foi avaliada pelo teste de qui-quadrado utilizando-se o procedimento FREQ do SAS (1985).

\section{RESULTADOS E DISCUSSÃO}

As dietas consumidas, com teor de $\mathrm{PB}$ ao redor de 15,5\% (Tab. 1), foram avaliadas pelos modelos do NRC (Nutrient..., 2001) e de Cornell v.5 (Evaluation..., 2009). Com base na estimativa dos modelos, a substituição de farelo de soja por NNP e polpa cítrica aumentou em $0,6 \%$ da MS o conteúdo dietético de proteína degradável no rúmen (PDR) e reduziu, na mesma proporção, o conteúdo de proteína não degradável (PND), indistintamente entre as fontes de NNP. Tanto o balanço estimado entre fluxo e a demanda de proteína metabolizável quanto o de energia foram positivos em todas as dietas.

O consumo de matéria seca caiu nos tratamentos com NNP, sem efeito sobre a produção diária de leite ou sólidos, resultando em tendência de ganho na relação entre o leite produzido e o consumo (Tab. 2). Golombeski et al. (2006) também observaram redução do consumo, sem o simultâneo decréscimo da produção leiteira, quando substituíram concentrados proteicos por $0,61 \%$ da dieta total de ureia complexada a cloreto de cálcio, inclusão semelhante à adotada neste trabalho. Entretanto, a inclusão de 1,9\% da dieta total de ureia em substituição ao farelo de soja reduziu a eficiência alimentar (Brito e Broderick, 2007), sugerindo que inclusões de NNP acima de recomendações tidas como clássicas, ao redor de $1 \%$ da dieta (Reid, 1953), podem não ser vantajosas.

Tabela 2. Desempenho e digestibilidade aparente de nutrientes no trato digestivo total de vacas leiteiras segundo os tratamentos

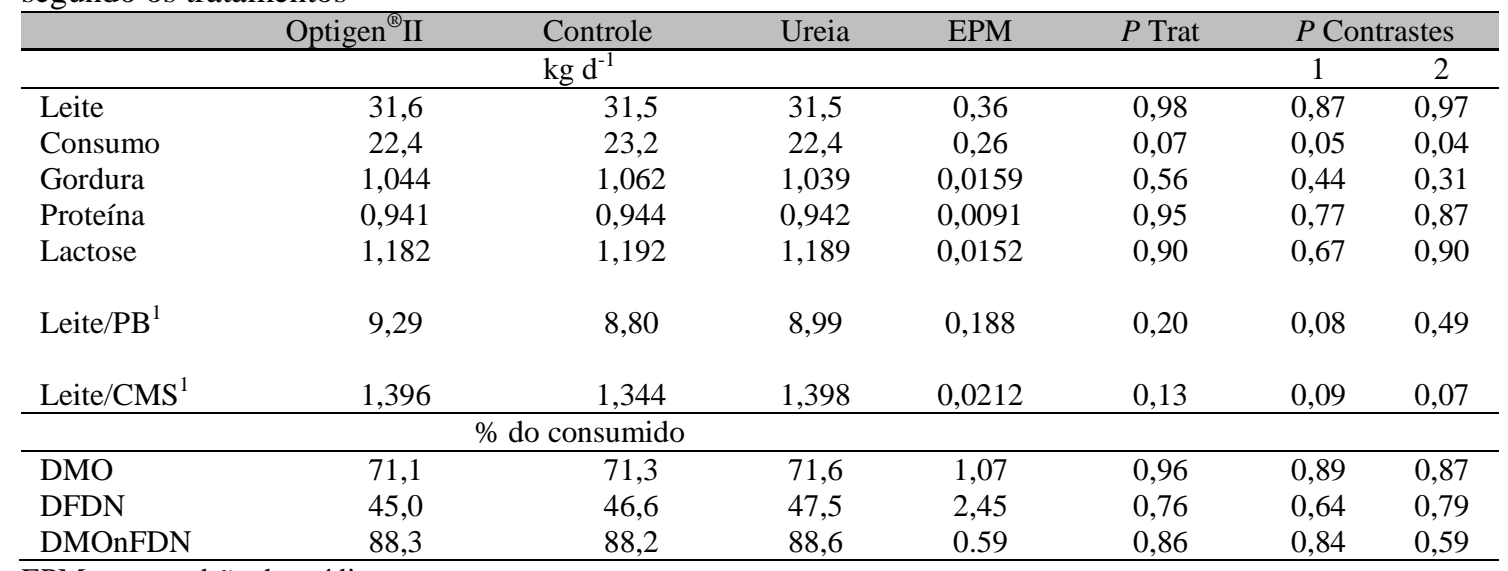

EPM: erro-padrão da média.

$P$ : valor de probabilidade para os efeitos de tratamento (P Trat) e para os contrastes Optigen ${ }^{\circledR} \mathrm{II}$ vs. controle (1) e ureia vs. controle (2).

${ }^{1} \mathrm{~kg}$ de leite por kg de proteína bruta (PB) ingerida e por kg de consumo de matéria seca (CMS).

DMO: digestibilidade aparente da matéria orgânica; DFDN: digestibilidade aparente da fibra em detergente neutro; DMOnFDN: digestibilidade aparente da matéria orgânica não fibrosa. 
A redução de consumo por baixa palatabilidade da ureia pode não ter sido o mecanismo prevalente no presente trabalho, pois o teor dietético das fontes de NNP foi baixo, e a ureia foi misturada a outros ingredientes em dieta completa. O encapsulamento do NNP no Optigen ${ }^{\circledR}$ II também seria um fator desfavorável à argumentação de que fatores sensoriais estariam envolvidos na resposta ao consumo. Wilson et al. (1975) observaram que a infusão intrarruminal de ureia foi tão depressora do consumo quanto a incorporação da ureia à dieta, demonstrando a possibilidade de mecanismo sistêmico.

Alguns mecanismos têm sido propostos para explicar o efeito negativo sistêmico de NNP sobre o consumo. A rápida hidrólise da ureia no rúmen poderia causar acidificação tóxica das células epiteliais (Visek, 1968) e alteração da motilidade ruminal (Juhász e Szegedi, 1983). Kertz et al. (1982) propuseram que a amônia liberada no rúmen poderia causar intoxicação subletal em bovinos. A rápida hidrólise da ureia em amônia no rúmen, sob condições de $\mathrm{pH}$ ruminal próximo da neutralidade, poderia favorecer a absorção da amônia não ionizada pela parede. Neste caso, a capacidade de ureagênese hepática poderia ser excedida, induzindo ao acúmulo de amônia no plasma (Symonds et al., 1981). O ciclo hepático da ureia também pode ter estimulado indiretamente o metabolismo oxidativo no fígado a partir de carbonos oxidáveis oriundos do catabolismo de aminoácidos, pois um dos carbonos na conversão de amônia a ureia vem do aspartato (Oba e Allen, 2003). Esse fato pode ter aumentado a produção líquida de ATP pelo fígado, capaz de deprimir o consumo (Allen, 2000).

A queda no consumo induzida por NNP foi acompanhada de alteração no comportamento ingestivo (Tab. 3). No tratamento ureia, foram observados maior número de refeições matinais e tendência de queda no tempo de ingestão matinal, e maior número de refeições matinais também ocorreu no tratamento Optigen ${ }^{\circledR} \mathrm{II}$. Conrad et al. (1977) observaram que a inclusão de $1,3 \%$ de ureia à dieta total de vacas leiteiras induziu à queda na duração da primeira refeição diária e no tempo por refeição, mesmo sem reduzir o consumo total de matéria seca, pois houve compensação por aumento no número de refeições e na taxa de ingestão, semelhante numericamente ao observado neste trabalho. A similaridade na resposta em comportamento ingestivo nos tratamentos ureia e Optigen ${ }^{\circledR}$ II sugere que o mecanismo envolvido na resposta de consumo foi comum às dietas que continham NNP.

Tabela 3. Proporção do consumo diário de matéria seca ao longo do dia e ingestão matinal observadas em vacas leiteiras segundo os tratamentos

\begin{tabular}{|c|c|c|c|c|c|c|c|}
\hline \multirow{2}{*}{ 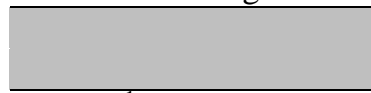 } & Optigen ${ }^{\circledR} \mathrm{II}$ & Controle & Ureia & \multirow[t]{2}{*}{ EPM } & $P$ Trat & \multicolumn{2}{|c|}{$P$ Contrastes } \\
\hline & \multicolumn{3}{|c|}{ \% do consumo diário } & & & 1 & 2 \\
\hline Manhã $^{1}$ & 32,0 & 32,9 & 34,2 & 1,12 & 0,42 & 0,59 & 0,44 \\
\hline Tarde $^{1}$ & 45,4 & 42,5 & 41,6 & 1,33 & 0,09 & 0,13 & 0,66 \\
\hline \multirow[t]{2}{*}{ Noite $^{1}$} & 22,5 & 24,6 & 24,2 & 1,00 & 0,31 & 0,15 & 0,76 \\
\hline & \multicolumn{3}{|c|}{ Min } & & & & \\
\hline Ingestão & 83 & 89 & 79 & 4,0 & 0,21 & 0,25 & 0,08 \\
\hline \multirow[t]{2}{*}{ Refeição condicionada $^{2}$} & 29 & 30 & 28 & 1,9 & 0,57 & 0,60 & 0,29 \\
\hline & \multicolumn{3}{|c|}{ min refeição ${ }^{-1}$} & & & & \\
\hline Tempo de refeição & 21 & 23 & 20 & 1,7 & 0,49 & 0,44 & 0,24 \\
\hline \multirow[t]{2}{*}{ Refeições } & 4,1 & 3,4 & 4,3 & 0,20 & 0,01 & 0,05 & $<0,01$ \\
\hline & & $\mathrm{g} \mathrm{min}^{-1}$ & & & & & \\
\hline Taxa de ingestão $^{2}$ & 91,0 & 87,3 & 95,8 & 6,54 & 0,65 & 0,69 & 0,36 \\
\hline
\end{tabular}

EPM: erro-padrão da média.

$P$ : valor de probabilidade para os efeitos de tratamento ( $P$ Trat) e para os contrastes Optigen ${ }^{\circledR}$ II vs controle (1) e ureia $v s$ controle (2).

${ }^{1}$ Manhã = seis às 12 horas; tarde $=12$ às 20 h; noite $=20$ às seis horas.

${ }^{2}$ Refeição condicionada: primeira refeição após oferecimento da dieta; taxa de ingestão: matéria seca consumida por minuto de ingestão matinal. 
A concentração de NUP duas horas após a alimentação matinal foi maior nos tratamentos com NNP que no controle (Tab. 4, Fig. 1), sugerindo que o teor de NUP imediatamente após o oferecimento matinal de alimentos foi determinante do consumo. No controle, o valor do pico diário de NUP foi similar e mais tardio que nos outros tratamentos (Fig. 1). O pico mais precoce de NUP pode estar associado à maior concentração de amônia no sangue, uma explicação plausível para a queda de consumo observada nos tratamentos com NNP, induzida pelos mecanismos já descritos.

Tabela 4. Concentração de nitrogênio ureico no leite (NUL) e no plasma (NUP) de vacas leiteiras segundo os tratamentos

\begin{tabular}{|c|c|c|c|c|c|c|c|}
\hline . & Optigen ${ }^{\circledR} \mathrm{II}$ & Controle & Ureia & EPM & $P$ Trat & \multicolumn{2}{|c|}{$P$ Contrastes } \\
\hline & \multicolumn{3}{|c|}{$\mathrm{mg} \mathrm{dL}^{-1}$} & & & 1 & 2 \\
\hline \multicolumn{7}{|c|}{$\operatorname{mg~dL^{-1}}$} & $<0,01$ \\
\hline NUP & 17,6 & 17,6 & 18,0 & 0,45 & 0,78 & 0,96 & 0,52 \\
\hline \multicolumn{8}{|c|}{$\min \mathrm{d}^{-1}$} \\
\hline NUP $>21$ & 41 & 46 & 105 & 27,8 & 0,21 & 0,89 & 0,15 \\
\hline \multicolumn{5}{|c|}{$\%$ das amostras } & \multicolumn{3}{|c|}{ P Qui-Quadrado } \\
\hline Frequência & 10,2 & 9,3 & 23,2 & & & $<0,01$ & \\
\hline
\end{tabular}

EPM: erro-padrão da média.

$P$ : valor de probabilidade para os efeitos de tratamento ( $P$ Trat) e para os contrastes Optigen ${ }^{\circledR}$ II vs. controle (1) e ureia vs. controle (2).

NUP 2h: NUP duas horas após a alimentação da manhã; NUP>21: tempo de NUP acima de $21 \mathrm{mg} \mathrm{dL}^{-1}$; frequência: frequência de NUP acima de $22 \mathrm{mg} \mathrm{dL}^{-1}$.

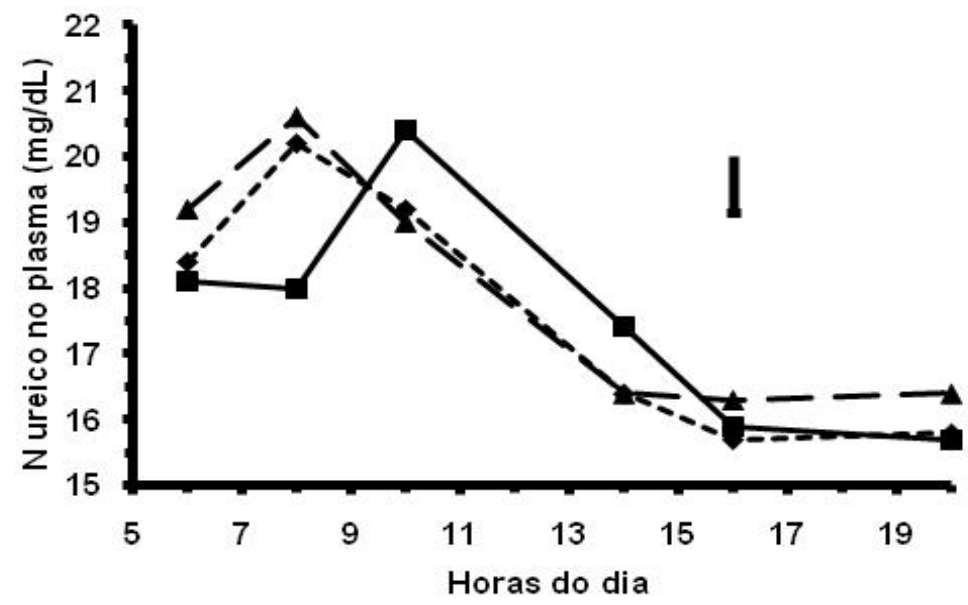

$\longrightarrow-$ Optigen II $\rightarrow-F$. soja $\rightarrow-$ Uréia

Figura 1. Nitrogênio ureico no plasma de vacas leiteiras segundo os tratamentos Optigen ${ }^{\circledR} \mathrm{II}\left(---_{--)}\right.$, controle (-匹-) ou ureia $(\boldsymbol{-} \boldsymbol{\Delta}-)$. Os animais foram alimentados às seis e às 14 horas. $P=0,98$ para efeito de tratamento; $P<0,01$ para efeito de tempo; $P=0,49$ para efeito da interação tratamento vs. tempo.

O tratamento Optigen ${ }^{\circledR}$ II resultou em NUP similar ao ureia até oito horas após a alimentação matinal e similar ao controle nos tempos de 10 e 14h (Fig. 1). O teor de NUL no Optigen ${ }^{\circledR} \mathrm{II}$ foi similar ao do controle e mais baixo que no de ureia (Tab. 4). O valor da concentração de NUL 
nos tratamentos refletiu a frequência diária de NUP acima de $22 \mathrm{mg} \mathrm{dL}^{-1}$, e não refletiu o teor médio de NUP ao longo do dia (Fig. 1). Entre vacas, a correlação positiva entre o NUP médio e o NUL foi de $0,70(P<0,01)$.

O oferecimento matinal de alimentos induziu ao pico no teor de NUP, enquanto a segunda alimentação diária não induziu a uma resposta similar (Fig. 1), mesmo com maior proporção do consumo entre 12 e 20 horas (Tab. 3). O pH do rúmen pode ter sido o fator responsável por essa resposta. $\mathrm{O}$ pH determina a forma de absorção da amônia pelo epitélio, difusão simples da forma não protonada ou absorção por canais de potássio da forma protonada (Reynolds e Kristensen, 2008). Em pH próximo da neutralidade, esperado em vacas leiteiras imediatamente após o fornecimento matinal de dieta completa (Salvador et al., 2008), predomina a forma não protonada e lipofílica da amônia, com alta velocidade de absorção (Abdoun et al., 2007), o que resultaria em maior fluxo de amônia para o sangue após a primeira alimentação. Na segunda alimentação diária, o $\mathrm{pH}$ ruminal estaria circadianamente mais baixo, levando à menor velocidade de absorção da amônia na forma protonada.

Outro mecanismo para a ausência de pico de NUP concomitantemente à segunda alimentação diária seria a possibilidade de maior sincronismo entre a liberação do nitrogênio dietético no rúmen e a degradação de carboidratos (Hall e Huntigton, 2008). A julgar pelo pico na concentração ruminal de ácidos graxos voláteis e pelo mínimo valor de $\mathrm{pH}$ diário, Salvador et al. (2008) observaram que o momento de máxima fermentação de carboidratos em vacas alimentadas de modo semelhante às deste experimento ocorreu a partir de oito horas da primeira alimentação diária. Maior velocidade de crescimento e assimilação de $\mathrm{N}$ por microrganismos ruminais, acoplado a menor $\mathrm{pH}$ do fluido, capaz de determinar a prevalência da forma protonada da amônia, podem ter determinado um menor fluxo de amônia do rúmen para o sangue no período da tarde.
Embora não validado cientificamente, em manejo alimentar similar ao adotado neste experimento, evitar o fornecimento de fontes de NNP na primeira alimentação diária pode reduzir a ocorrência de picos precoces de NUP. Redução no NUP, e provavelmente na amônia plasmática (Sinclair et al., 2000), pode ter efeito benéfico sobre a eficiência reprodutiva de vacas leiteiras (Butler, 1998). Essa estratégia também pode resultar em uso de NNP sem a queda observada no CMS, desejável em animais em balanço negativo de energia, e pode aumentar a eficiência de uso do nitrogênio dietético. Em contrapartida, o fornecimento concentrado de NNP na primeira alimentação diária seria uma estratégia plausível se o intuito fosse limitar o consumo em animais com alto balanço positivo de energia, visando obter ganho em eficiência alimentar ou para evitar deposição excessiva de gordura corporal, por restrição do consumo diário de energia.

Houve tendência de ganho na conversão da proteína bruta ingerida em leite no tratamento Optigen ${ }^{\circledR} \mathrm{II}$ (Tab. 2). Resultado semelhante foi observado por Galo et al. (2003) quando ureia de degradação lenta encapsulada com polímero substituiu concentrados proteicos. Entretanto, o balanço de nitrogênio não respondeu aos tratamentos (Tab. 5), resultado semelhante ao observado por Galo et al. (2003). A substituição de proteína de soja por NNP não resultou em aumento na perda de nitrogênio urinário e fecal, sendo, portanto, semelhantes ambientalmente.

Como vantagem ambiental, houve tendência de queda no volume diário de urina nas dietas com NNP, uma justificativa para a adoção desses alimentos em sistemas de produção de leite sujeitos a alta regulação ambiental. A tendência de aumento do volume urinário no controle pode ser atribuída à maior ingestão de $\mathrm{N}$ neste tratamento. Reynal e Broderick (2005) verificaram redução no volume urinário e na excreção de $\mathrm{N}$ com a redução da proteína degradável no rúmen da dieta. Maior consumo de $\mathrm{N}$ pode induzir aumento no consumo e excreção de água pela urina (Bannink et al., 1999). 
Tabela 5. Balanço de nitrogênio e excreção diária de alantoína na urina de vacas leiteiras segundo os tratamentos

\begin{tabular}{|c|c|c|c|c|c|c|c|}
\hline & Optigen ${ }^{\circledR} \mathrm{II}$ & Controle & Ureia & EPM & $P$ Trat & \multicolumn{2}{|c|}{$P$ Contrastes } \\
\hline \multicolumn{5}{|c|}{$\mathrm{g} \mathrm{d}^{-1}$} & & 1 & 2 \\
\hline $\mathrm{N}$ ingerido & 553 & 570 & 558 & 5,7 & 0,13 & 0,05 & 0,16 \\
\hline N no leite & 147 & 149 & 148 & 1,6 & 0,82 & 0,54 & 0,71 \\
\hline $\mathrm{N}$ fecal & 187 & 193 & 187 & 7,7 & 0,80 & 0,59 & 0,55 \\
\hline N urinário & 146 & 153 & 156 & 6,9 & 0,59 & 0,48 & 0,75 \\
\hline $\mathrm{N}$ retido & 72 & 74 & 68 & 11,6 & 0,91 & 0,91 & 0,68 \\
\hline \multicolumn{8}{|c|}{$\mathrm{L} \mathrm{d}^{-1}$} \\
\hline Urina & 25,0 & 27,5 & 24,6 & 0,99 & 0,12 & 0,09 & 0,05 \\
\hline \multicolumn{8}{|c|}{ mmoles d $^{-1}$} \\
\hline Alantoína & 122,3 & 120,6 & 121,7 & 14,49 & 0,99 & 0,93 & 0,96 \\
\hline Alan/Creat & 1,23 & 1,14 & 1,07 & 0,146 & 0,73 & 0,64 & 0,75 \\
\hline
\end{tabular}

EPM: erro-padrão da média.

P: valor de probabilidade para os efeitos de tratamento (P Trat) e para os contrastes Optigen ${ }^{\circledR}$ II vs. controle (1) e ureia vs. controle (2).

Alan/Creat: relação entre o teor de alantoína e o de creatinina na urina.

A perda de $\mathrm{N}$ urinário foi menor que a perda de $\mathrm{N}$ fecal (Tab. 5). Cerca de $27 \%$ do $\mathrm{N}$ ingerido foi perdido pela urina, e cerca de $26 \%$ foi incorporado ao leite, coerente com as estimativas obtidas pelo Cornell v.5 (Evaluation..., 2009), valores não diferentes entre tratamentos $(P>0,64)$. O valor da proporção do $\mathrm{N}$ ingerido secretado no leite é similar ao valor médio de 27\% da meta-análise de Chase (2008), gerado a partir de dados publicados de 334 tratamentos oriundos de 62 experimentos. Tamminga (1992) relatou que, nas condições da Holanda, onde pastagens de clima temperado com conteúdo elevado de $\mathrm{N}$ são rotineiramente utilizadas como ingrediente dietético, a proporção do $\mathrm{N}$ ingerido perdido pela urina seria ao redor de $50 \%$, e o $\mathrm{N}$ incorporado ao leite ao redor de $19 \%$, resultado bem distinto dos valores observados experimentalmente e do predito por modelagem. A diferença nas estimativas pode ser em decorrência da diferença nas forragens, sugerindo que dietas baseadas em silagem de milho seriam preferíveis ambientalmente em comparação a dietas baseadas em pastagem de clima temperado, pois a maior proporção de perda urinária é indesejável devido à rápida conversão de ureia em amônia e óxido nitroso (Marini e Amburgh, 2005).

Não foi detectado efeito de tratamento sobre a digestibilidade aparente de nutrientes no trato digestivo total (Tab. 2) e sobre o consumo diário de matéria orgânica digestível, em média $15,0 \mathrm{~kg}$ $(P=0,54)$. Diferenças no fluxo de nitrogênio do rúmen, de ocorrência provável a se julgar pelo teor de NUP ao longo do dia (Fig. 1), não se refletiram na função digestiva. A ausência de efeito de tratamento sobre a síntese de proteína microbiana, estimada tanto pela excreção diária de alantoína na urina como pela relação entre alantoína e creatinina (Tab. 5), também suporta essa observação, similar ao verificado por Galo et al. (2003) e Brito e Broderick (2007), quando também avaliaram a substituição de concentrados proteicos por NNP. A extensa reciclagem de nitrogênio em ruminantes é uma explicação plausível para a ausência de resposta em função digestiva à atuação sobre o sincronismo entre a digestão de proteína e a de carboidratos (Lapierre e Lobley, 2001; Reynolds e Kristensen, 2008).

\section{CONCLUSÕES}

A substituição de farelo de soja por polpa cítrica e NNP, em dietas capazes de suprir a demanda teórica de aminoácidos essenciais metabolizáveis, resultou em tendência de aumento na eficiência alimentar, por apresentar produção de leite semelhante com menor consumo de matéria seca. Entretanto, a ureia encapsulada não aumentou o teor de NUL comparativamente à ureia, e o pico de NUP, mais precoce após a alimentação matinal, foi relacionado ao menor CMS, enquanto maior frequência de valores de NUP, acima de $22 \mathrm{mgdL}^{-1}$, foi relacionada ao maior teor de NUL entre tratamentos. A atuação sobre a forma 
do nitrogênio alimentar não determinou a digestibilidade de nutrientes no trato digestivo total, a síntese de proteína microbiana no rúmen, ou o balanço de N. A substituição parcial do N em farelo de soja por NNP foi adequada ambientalmente.

\section{AGRADECIMENTOS}

Os autores agradecem a confiança e o financiamento da Alltech do Brasil Agroindustrial Ltda., representada pelo seu diretor, Dr. Ari Fisher, e pelo gerente técnico de ruminantes, Dr. Marcelo de Queiroz Manella.

\section{REFERÊNCIAS BIBLIOGRÁFICAS}

ABDOUN, K.; STUMPFF, F.; MARTENS, H. Ammonia and urea transport across the rumen epithelium: a review. Anim. Health Res., v.7, p.1-17, 2007.

ALLEN, M.S. Effects of diet on short-term regulation of feed intake by lactating dairy cattle. J. Dairy Sci., v.83, p.1598-1624, 2000.

BANNINK, A.; VALK, H.; VUUREN, A.M. Intake and excretion of sodium, potassium, and nitrogen and the effects on urine production by lactating dairy cows. J. Dairy Sci., v.82, p.1008-1018, 1999.

BRITO, A.F.; BRODERICK, G.A. Effects of different protein supplements on milk production and nutrient utilization in lactating dairy cows. J. Dairy Sci., v.90, p.1816-1827, 2007.

BUTLER, W.R. Review: effect of protein nutrition on ovarian and uterine physiology in dairy cattle. J. Dairy Sci., v.81, p.2533-2539, 1998.

CHASE, L.E. How efficienthy are your cows using ration nitrogen? [2008]. Disponível em: $<$ http://www.extension.org/pages/How_Efficiently_Ar e_Yours_Cows_Using_Ration_Nitrogen\%3F./>. Acessado em: 12 nov. 2008.

CHEN, X.B.; GOMES, J. Estimation of microbial protein supply to sheep and cattle based on urinary excretion of purine derivatives: an overview of the technical details. Bucksburn: International Feed Research Unit, 1995. 20p.

CONRAD, H.R.; BAILE, C.A.; MAYER, J. Changing meal patterns and suppression of feed intake with increasing amounts of dietary nonprotein nitrogen in ruminants. J. Dairy Sci., v.60, p.1725-1733, 1977.

EVALUATION in application of the CPM-Dairy nutrition model. Version 3.0.10. [2009]. Disponível em: $\quad$ <http://www.cpmdairy.com/Index.html>. Acessado em: 30 jun. 2009.
GALO, E.; EMANUELE, S.M.; SNIFFEN, C.J. et al. Effects of a polymer-coated urea product on nitrogen metabolism in lactating Holstein dairy cattle. J. Dairy Sci., v.86, p.2154-2162, 2003.

GOLOMBESKI, G.L.; KALSCHEUR, K.F.; HIPPEN, A.R. et al. Slow-release urea and highly fermentable sugars in diets fed to lactating dairy cows. J. Dairy Sci., v.89, p.4395-4403, 2006.

HALL, M.B.; HUNTIGTON, G.B. Nutrient synchrony: sound in theory, elusive in practice. $J$. Animal Sci., v.86, p.E287-E292, 2008.

HARRISON, G.A.; TRICARICO, J.M.; DAWSON, K.A. Effects of urea and Optigen ${ }^{\circledR}$ II on ruminal fermentation and microbial protein synthesis in rumen-simulating cultures. In: NUTRITIONAL BIOTECHNOLOGY IN THE FEED AND FOOD INDUSTRIES, 22., 2006, Lexington. Proceedings... Lexington: Alltech, 2006. (CD-ROM).

INOSTROZA, J.F.; SHAVER, R.D.; CABRERA, V.E. et al. Effect of diets containing a controlledrelease urea product on milk yield, milk composition, and milk component yields in commercial Wisconsin dairy herds and economic implications. The Prof Anim Sci, v.26, p.175-180, 2010.

JUHÁSZ, B.; SZEGEDI, B. Effects of disturbances of acid-base equilibrium on the activity of the rumen. Act. Phys. Hung., v.62, p.7-17, 1983.

KERTZ, A.F.; KOEPKE, M.K.; DAVIDSON, L.E. et al. Factors influencing intake of high urea-containing rations by lactating dairy cows. J. Dairy Sci., v.65, p.587-604, 1982.

LAPIERRE, H.; LOBLEY, G.E. Nitrogen recycling in the ruminant: a review. J. Dairy Sci., v.84, suppl., p.E223-E236, 2001.

LITTELL, R.C.; MILLIKEN, G.A.; STROUP, W.W. et al. $S A S^{\circledR}$ system for mixed models. Cary: SAS Institute, 1996. 633p.

MARINI, J.C.; AMBURGH, M.E. Partition of nitrogen excretion in urine and the feces of Holstein replacement heifers. J. Dairy Sci., v.88, p.1778-1784, 2005.

NUTRIENT requirements of dairy cattle. 7.ed., rev. Washington: National Academy, 2001. 381p.

OBA, M.; ALLEN, M.S. Extent of hypophagia caused by propionate infusion was related to plasma glucose concentration in lactating dairy cows. J. Nutr., v.133, p.1105-1112, 2003.

OFFICIAL methods of analysis. 12.ed. Washington, DC: AOAC, 1975. v.1, 1094p.

OFFICIAL methods of analysis. 15.ed. Washington, DC: AOAC, 1990. v.1, 1117p. 
REID, J.T. Urea as a protein replacement for ruminants: a review. J. Dairy Sci., v.36, p.955-996, 1953.

REYNAL, S.M.; BRODERICK, G.A. Effect of dietary level of rumen-degraded protein on production and nitrogen metabolism in lactating dairy cows. $J$. Dairy Sci., v.88, p.4045-4064, 2005.

REYNOLDS, C.K.; KRISTENSEN, N.B. Nitrogen recycling through the gut and the nitrogen economy of ruminants: an asynchronous symbiosis. J. Anim. Sci., v.86, p.E293-E305, 2008.

SALVADOR, S.C.; PEREIRA, M.N.; SANTOS, J.F. et al. Resposta de vacas leiteiras à substituição total de milho por polpa cítrica e à suplementação com microminerais orgânicos: I., consumo e digestão. Arq. Bras. Med. Vet. Zootec., v.60, p.682-690, 2008.

SINCLAIR, K.D.; SINCLAIR, L.A.; ROBINSON, J.J. Nitrogen metabolism and fertility in cattle: I., adaptive changes in intake and metabolism to diets differing in their rate of energy and nitrogen release in the rumen. J. Anim. Sci., v.78, p.2659-2669, 2000.
SMITH, K.A.; FROST, J.P. Nitrogen excretion by farm livestock with respect to land spreading requirements and controlling nitrogen losses to ground and surface waters: part 1: cattle and sheep. Liv. Prod. Sci., v.71, p.173-181, 2000.

SYMONDS, H.W.; MATHER, D.L.; COLLIS, K.A The maximum capacity of the liver of the adult dairy cow to metabolize ammonia. Br. J. Nutr., v.46, p.481486, 1981

TAMMINGA, S. Nutrition management of dairy cows as a contribution to pollution control. J. Dairy Sci., v.75, p.345-357, 1992.

VISEK, W.J. Nitrogen utilization by the ruminant: some aspects of ammonia toxicity in animal cells. $J$. Dairy Sci., v.51, p.286-295, 1968.

WILSON, G.; MARTZ, F.A.; CAMPBELL, J.R. et al. Evaluation of factors responsible for reduced voluntary intake urea diets for ruminants. J. Anim. Sci., v.41, p.1431-1437, 1975. 